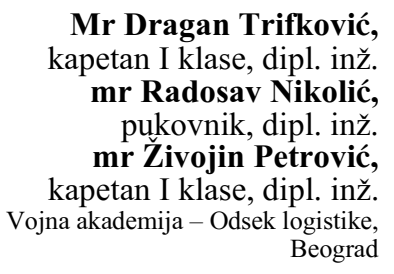

Mr Dragan Trifković, mr Radosav Nikolić,

pukovnik, dipl. inž

mr Živojin Petrović, kapetan I klase, dipl. inž. Beograd

\section{MERENJE TORZIONIH OSCILACIJA POMOĆU MERNIH TRAKA}

UDC: $514.013: 681.518 .3$

Rezime:

U ovom radu prikazan je metod merenja torzionih oscilacija mehaničkih sistema na osnovu merenja torzionog napona pomoću mernih traka. Ovaj metod naročito je pogodan za proveru nivoa naprezanja elemenata sistema, koji prenose promenljive obrtne momente $i$ torziono osciluju. Osim toga, mogu se odredivati $i$ kritične brzine obrtanja elemenata sistema, pri kojima se javljaju rezonantna naprezanja i otkazi sistema, kao što su: pojačana buka, trošenje zupčanika, zamor materijala, oštećenja i lomovi vratila, spojnica i sl. Predložen je merni lanac u kojem centralno mesto zauzima savremeni mobilni merni sistem Spider 8, koji omogućava merenje, obradu i prikaz rezultata pomoću računara.

Ključne reči: torzione oscilacije, merne trake, merna oprema, normalni i tangencijalni naponi, rezonantna brzina, vratilo.

\title{
MEASUREMENT OF TORSIONAL VIBRATIONS BY USING STRAIN GAGES
}

Summary:

In this work the measuring method of torsion vibrations is presented according to the measurement of torsion stress using strain gages. This method is particularly suitable in checking the system elements strain level that transfers changeable torsion moments and oscillate torsionally. Besides that, the system elements critical velocity rotation can be estimated, followed by the resonant strain and problems in the function of that system such as: amplified noise, wearing-out of gears, fatigue crack, damage and break of shafts and junctions etc. The measuring chain is proposed in which the central part is a contemporary mobile system Spider 8, which enables measurement, processing and displays measured results on a computer.

Key words: torsional vibration, strain gages, measurement equipment, normal and shear stresses, resonant speed, shaft.

\section{Uvod}

Mehaničke oscilacije elastičnih sistema, pri kojima dolazi do deformacija pri uvijanju, nazivaju se torzionim oscilacijama. One se najčešće javljaju na vratilima koja prenose promenljive obrtne momente. U slučaju kada se frekvencija pobude poklopi sa frekvencijom slobodnih oscilacija, javlja se rezonanca. Duži rad sistema u rezonantnom režimu, ili u blizini tog režima, može prouzrokovati pojačanu buku, trošenje zupčanika, zamor materijala, a u nekim slučajevima i oštećenja i lomove vratila i drugih elemenata sistema.

Nivo torzionih oscilacija važan je dijagnostički parametar za ocenu tehničkog stanja sistema. Razlozi za merenje ovog parametra na realnom sistemu mo- 
gu biti: dijagnostika i monitoring sistema, unapređenje i razvoj sistema, razvoj metoda projektovanja i konstruisanja, identifikacija parametara matematičkog modela i dr.

Za merenje torzionih oscilacija može se odabrati jedna od sledećih veličina: torzioni napon $\tau\left[\mathrm{N} / \mathrm{m}^{2}\right]$, ugaoni položaj $\alpha$ [rad], ugaona brzina $\dot{\alpha}[\mathrm{rad} / \mathrm{s}]$, ugaono ubrzanje $\ddot{\alpha}\left[\mathrm{rad} / \mathrm{s}^{2}\right]$.

Za merenje ovih veličina mogu da se koriste sledeći davači [1]: merne trake (postavljene na pojedine delove vratila $\mathrm{i}$ povezane u merni most), davači torzionih oscilacija (induktivni, piezo-električni i elektrodinamički), enkoderi visoke rezolucije (tanke ploče sa par hiljada podeoka po krugu, koji se ugrađuju na slobodan kraj vratila), nazubljene ploče ili već postojeći zupčanici ugrađeni na vratilima, kao i beskontaktni davači odstojanja (analogni i digitalni).

Merni signal može se prikazivati na različite načine, $i$ to kao: realna funkcija (npr. vremenski zapis) u obliku jednačine ili grafički, kompleksna funkcija (spektar) u obliku jednačine ili grafički i skalarna veličina (srednja vrednost, RMS vrednost i dr.).

Merenje torzionih oscilacija na realnom objektu često je otežano i uslovljeno različitim ograničenjima u pogledu smeštaja davača (mogućnost ugradnje i skidanja), rada na različitim režimima i sl. Kada se za merenje torzionih oscilacija koriste merne trake treba imati u vidu da se torzioni napon meri samo u poprečnom preseku vratila, na mestu na kojem su postavljene merne trake. Osim toga, upotrebom mernih traka ne dobija se istovremeno informacija o trenutnom ugaonom položaju vratila. Zbog toga je potrebno, osim torzionog napona, meriti i položaj vratila, kako bi se mogle definisati torzione oscilacije i sa aspekta njihove pobude. S druge strane, da bi se odredili položaji kritičnih brzina pri kojima se javljaju rezonantne torzione oscilacije, neophodno je istovremeno, sa merenjem torzionog napona, meriti i brzinu obrtanja vratila.

\section{Merenje napona torzije na vratilu pomoću mernih traka}

Upotrebom mernih traka na vratilima, koja su izložena uvijanju, mogu se meriti: normalni i tangencijalni naponi, obrtni moment (odnosno snaga koju vratilo prenosi), kao i deformacije vratila. Vratilo opterećeno na uvijanje izloženo je naprezanju u dve ose. Glavni normalni naponi javljaju se pod uglom od $\pm 45^{\circ} \mathrm{u}$ odnosu na uzdužnu osu. Za merenje naprezanja koja potiču od normalnih napona koriste se $X$ rozete, a posebno $V$ oblika sa osama merne mreže pod uglom $\pm 45^{\circ}$ u odnosu na uzdužnu osu vratila. Ose merne mreže moraju se poklapati sa pravcima glavnih napona (slika 1). Zadovoljavajući rezultati mogu se dobiti jedino pravilnim merenjem. Odstupanje osa merne mreže za ugao $\alpha$ daje grešku merenja $x[2]$ :

$x=(\cos 2 \alpha-1) 100 \%$

Ako je greška u postavljanju merne trake $\alpha=5^{\circ}$, greška merenja biće dovoljno mala i iznosi $1,6 \%$. Veće greške pri merenju mogu se javiti, kako usled nesimetričnog postavljanja mernih traka, tako i zbog nedovoljne kompenzacije po- 
stojećih normalnih naprezanja i naprezanja zbog savijanja. Za merenje je najbolje izabrati pun merni most. Pri prenosu mernog signala sa obrtnih vratila, zbog promenljivog kontaktnog otpora (ako se koristi jedna polovina mosta i kontaktni prenos sa kliznim prstenovima, tzv. sliprings) u mernom mostu može se pojaviti veća greška merenja. Zbog toga je najbolje koristiti pun most i beskontaktni prenos mernog signala sa mosta. Upotrebom punog mosta dobro se kompenzuje šum koji potiče od normalnih i savojnih opterećenja, ukoliko se merne trake postave na vratilo na način kako je prikazano na slici 1 .

Glavni normalni naponi $\sigma_{1,2}$ mogu se izračunati iz izmerenih dilatacija $\varepsilon_{1,2}$, prema formulama za naponsko stanje $\mathrm{u}$ dve ose (naprezanje u dva pravca) [2], [4]:

$$
\begin{gathered}
\sigma_{1}=\frac{E}{1-\mu}\left(\varepsilon_{1}+\mu \varepsilon_{2}\right), \\
\sigma_{2}=\frac{E}{1-\mu}\left(\varepsilon_{2}+\mu \varepsilon_{1}\right)
\end{gathered}
$$

gde je:

$\sigma_{1,2}-$ glavni normalni naponi $\left[\mathrm{N} / \mathrm{m}^{2}\right]$,

$E$ - modul elastičnosti $\left[\mathrm{N} / \mathrm{m}^{2}\right]$,

$\varepsilon_{1,2}$ - relativne dilatacije traka,

$\mu$-Puasonov koeficijent.

Za vratila opterećena na uvijanje važi relacija:

$\left|\varepsilon_{1}\right|=\left|\varepsilon_{2}\right|, \quad \varepsilon_{2}=-\varepsilon_{1}$

Ako se merne trake povežu u jednu polovinu mosta, tada $\varepsilon_{2}$ menja predznak, pa je vrednost dilatacije:

$\varepsilon_{1}=\varepsilon_{1}-\left(\varepsilon_{2}\right)=\left|\varepsilon_{1}\right|+\left|\varepsilon_{2}\right|=2 \varepsilon$

a)

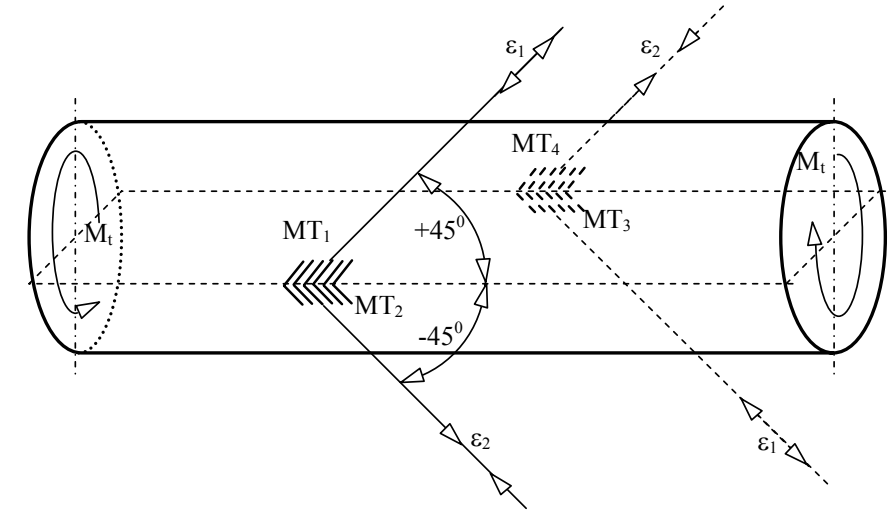

b)
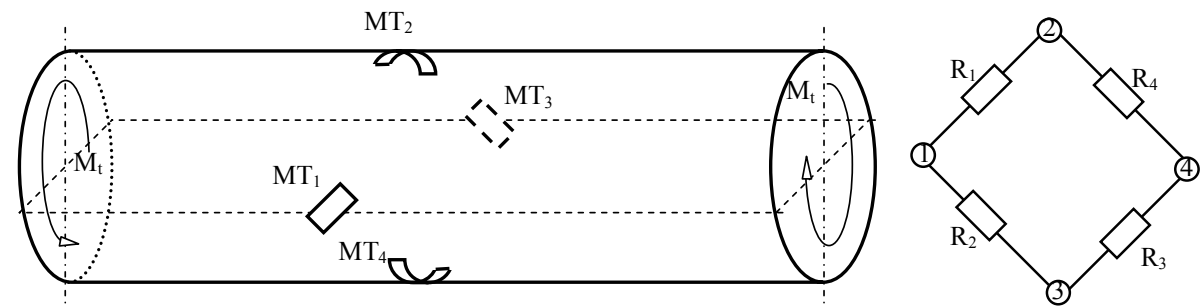

Sl. 1 - Vratilo sa postavljenim mernim trakama i njihove pozicije na mernom mostu, pri primeni: a) specijalnih X rozeta, b) pojedinačnih mernih traka 
Ista analogija važi i za pun most pa se jednačine (2) mogu napisati u obliku:

$\sigma_{1,2}= \pm \frac{1}{2} \frac{E}{1-\mu}(1-\mu) \varepsilon_{i}-$ za polovinu mosta

$\sigma_{1,2}= \pm \frac{1}{4} \frac{E}{1-\mu}(1-\mu) \varepsilon_{i}-$ za pun most

Tangencijalni napon $\tau$ menja se po poprečnom preseku, tako da je $\tau=0 \mathrm{u}$ centru preseka, do maksimalne vrednosti na obodu (slika 2):

$\tau \varepsilon_{\max }=2 \varepsilon_{45^{\circ}} G\left\{\begin{array}{l}\varepsilon_{i} G-\text { za polovinu mosta } \\ \frac{1}{2} \varepsilon_{i} G-\text { za pun most }\end{array}\right.$

gde je:

$\tau_{\max }-$ maksimalna vrednost tangencijalnog napona $\left[\mathrm{N} / \mathrm{m}^{2}\right]$,

$G-$ modul klizanja $\left[\mathrm{N} / \mathrm{m}^{2}\right]$.

Modul klizanja $G$ izračunava se pomoću obrasca:

$G=\frac{E}{2} \frac{1}{1+\mu}=\frac{E}{2(1+\mu)} \approx 0,385 E$ za $\mu=0,3$
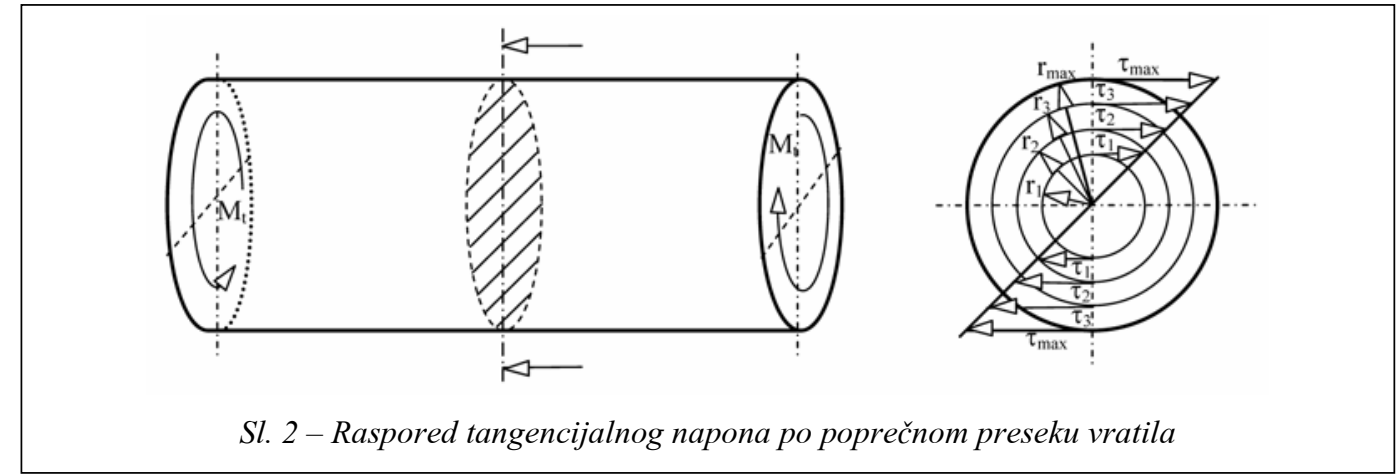

Sl. 2 - Raspored tangencijalnog napona po poprečnom preseku vratila
Moment torzije $\mathrm{M}_{\mathrm{t}}$ može se izračunati pomoću tangencijalnog napona $\tau_{\max }$ i polarnog otpornog momenta $\mathrm{W}_{0}$ :

$M_{t}=\tau_{\max } W_{0}=\left\{\begin{array}{l}\varepsilon_{i} G W_{0}-\text { za polovinu mosta } \\ \frac{1}{2} \varepsilon_{i} G W_{0}-\text { za pun most }\end{array}\right.$

gde je:

$M_{t}$ - moment torzije [Nm],

$W_{0}$ - polarni otporni moment $\left[\mathrm{m}^{3}\right]$.

Polarni otporni moment $\mathrm{W}_{0}$ zavisi od oblika poprečnog preseka, a za vratilo kružnog poprečnog preseka izračunava se prema izrazu:

$$
W_{0}=\frac{\pi d^{3}}{16} \approx 0,2 d^{3}
$$

gde je:

$d$-prečnik vratila $[\mathrm{m}]$.

Deformacije vratila pri uvijanju su ugao uvijanja $\theta$ i ugao klizanja $\gamma$ (slika 3 ), a izračunavaju se pomoću izraza:

$$
\gamma=\frac{\tau_{\max }}{G}, \theta=2 \frac{1}{d} \gamma=\left\{\begin{array}{l}
2 \varepsilon_{i} \frac{l}{d}-\text { za polovinu } \\
\text { mosta } \\
\varepsilon_{i} \frac{l}{d}-\text { za pun most }
\end{array}\right.
$$




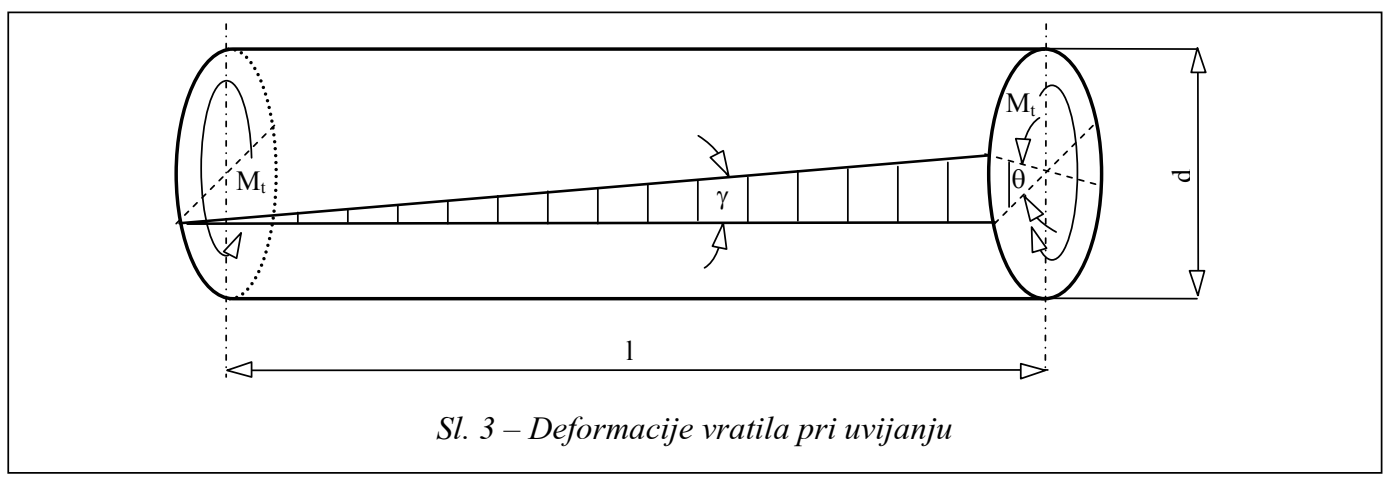

gde je:

$\theta$ - ugao uvijanja [rad],

$\gamma$ - ugao klizanja [rad],

$l$ - dužina posmatranog isečka vratila [m].

\section{Izbor opreme za merenje torzionih oscilacija}

Izbor merne opreme za merenje torzionih oscilacija uslovljen je, pre svega, tipom merene veličine, karakteristikama objekta merenja, raspoloživošću i mogućnostima nabavke opreme. Osim osnovnog zahteva da merni lanac ne izaziva promene merenog objekta, pri izboru merne opreme postavlja se i niz drugih zahteva koji se odnose na: frekvenciju i rezoluciju merenja, kontinuirano merenje i memorisanje izmerenih vrednosti $u$ realnom vremenu, A/D konverziju mernog signala, obradu i prikazivanje rezultata (korišćenje savremenog hardvera i softvera), kvalitet davača torzionih oscilacija, mogućnosti upravljanja radom merenog objekta, mobilnost i mogućnost rukovanja opremom.

Merenje torzionih oscilacija pomoću mernih traka ranije se retko primenjivalo zbog prisustva šuma u osnovnom signalu, koji ima visoke frekvencije i male amplitude. Zbog toga se signal morao višestruko pojačavati. Savremena merna oprema, i odgovarajući softveri za obradu izmerenih vrednosti, ove nedostatke u znatnoj meri ublažavaju. Za merenje nivoa torzionih oscilacija upotrebom mernih traka može se koristiti mobilni merni sistem Spider 8 (proizvođač HBM - Hottinger Baldwin Messtechnik iz Nemačke).

Sistem Spider 8 (slika 4) višekanalna je elektronska jedinica za paralelno merenje dinamičkih veličina pomoću računara [3]. Predstavlja adekvatnu zamenu za merne sisteme sa velikim brojem komponenti (prekidača, potenciometara, kartica sa ulazno-izlaznim adresama i dr.), jednostavno se povezuje sa računarom preko priključka za štampač i brzo priprema za merenja. Svaki kanal obezbeđuje pobudu za pasivne četvoropolne pojačavače, filtere i vlastiti pretvarač. Svi A/D pretvarači rade sinhronizovano i podržavaju preko 9600 merenja u sekundi (po svakom kanalu) sa rezolucijom od 16 bita.

Osnovna jedinica sistema Spider 8, sa četiri merna pojačavača noseće frekvencije $4,8 \mathrm{kHz}$, koji su stabilni i neosetljivi na interferenciju, omogućava merenja raznih mehaničkih veličina (pomak, broj obrtaja, moment, snaga, pritisak i dr.) pomoću mernih traka i induktivnih četvoropola. Dva kanala mogu se alternativno koristiti kao brojači impulsa. Sistem se može proširiti na 8 kanala u jednom uređaju, ili na svih 64 ka- 
nala sa 8 uređaja. Za proširenje namene uređaja mogu se koristiti dva modula. Jedan modul je dodatni CF kanal sa pojačavačem (sa nosećom frekvencijom), a drugi je sa električnim izolovanim ulazima za naponske ili strujne signale sa različitih davača. Sve komponente povezane su sa elektronikom koju kontroliše mikroprocesor.
Napajanje se obezbeđuje preko univerzalnog bloka iz integrisane reverzibilne baterije ili autoadaptera (12V DC). Po uključenju računara elektronika za distribuciju napajanja automatski detektuje moguće opcije napajanja. Uređaj za neprekidno napajanje dozvoljava promenu napajanja bez prekidanja merenja.

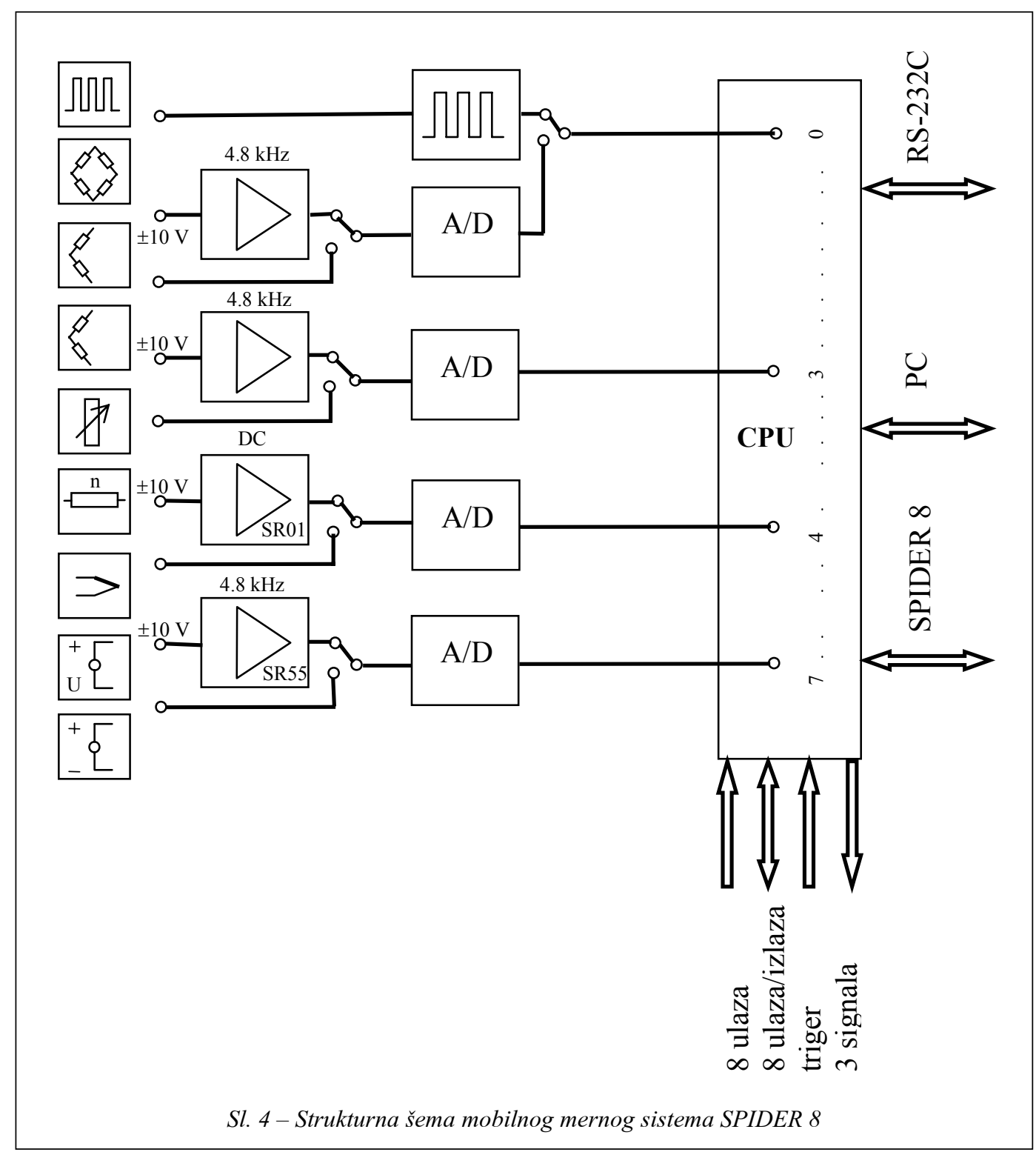


Svaki merni kanal podržava: pobu$\mathrm{du}$ senzora, prilagođenje signala, A/D konverziju i filtriranje. Visoka elektromagnetna otpornost, standardni konektor, kao i mogućnost potpune kontrole kompletnog mernog sistema pomoću računara, poboljšavaju metode merenja (veća pouzdanost i kraće vreme potrebno za inicijalizaciju mernog sistema).

$\mathrm{Na}$ osnovnu jedinicu i modul SR55 za proširenje mogu se povezati: merne trake i merni pretvarači preko kola u pun most ili polovinu mosta, induktivni četvoropoli preko kola u pun most ili polovinu mosta, potenciometarski četvoropoli, merni moduli sa strujnim ili naponskim izlazom $( \pm 200 \mathrm{~mA}, \pm 10 \mathrm{~V})$, kanali 0 i 1 u osnovnoj jedinici mogu se koristiti alternativno za impulse frekvencija preko $100 \mathrm{kHz}$ (enkoderi, rizolveri i taho generatori).

$\mathrm{Na}$ osnovnu jedinicu i na karticu SR30 mogu se priključiti: merne trake i merni pretvarači preko kola u pun most ili polovinu mosta, potenciometarski četvoropoli, termospojevi (tipa J, K, T i S), otporni termoelementi (Pt100 i Pt1000), merni moduli sa strujnim ili naponskim izlazom $( \pm 200 \mathrm{~mA}, \pm 10 \mathrm{~V})$.

Pojačavači sa nosećom frekvencijom od 4,8 kHz koriste se za pasivne četvoropole i pogodni su za merne trake i induktivne četvoropole. Oni daju analogni signal čija je širina spektra preko $200 \mathrm{~Hz}$. Posle pojačanja signala, $u$ analognoj sekciji, obavlja se A/D konverzija u osam potpuno sinhronizovanih 16-bitnih A/D konvertora (slika 4). Konverzija se vrši bez vremenskog odstupanja (bez multipleksera), čime se izbegavaju fazne greške u toku akvizicije mernih veličina, po- sebno kada se koristi veliki broj kanala. Maksimalna frekvencija uzorkovanja, koja može da se postavi, iznosi preko 9600 odbiraka u sekundi, a rezolucija od 16 bita ne zavisi od broja aktivnih kanala.

Inicijalizacija mernog sistema Spider 8 i razmena mernih veličina u digitalnom obliku u dvobajtnom formatu obavlja se preko priključka za štampač. Razmena podataka može se ostvariti brzinom od 75000 mernih podataka u sekundi. To znači da se za prikupljanje i obradu podataka može koristiti bilo koji PC ili Notebook bez posebne kartice, interfejsa ili PCMCIA kartice. Drugi paralelni port može se koristiti za povezivanje sa štampačem ili drugom jedinicom sistema Spider 8 . Na taj način može se uvezati maksimalno 8 jedinica sistema Spider 8 , formirajući tako 64-kanalni sistem koji funkcioniše kao jedinstven sistem. Pri povezivanju na računar nije potrebno posebno adresiranje. Ako računar nema raspoloživi port za štampač, komunikacija se može ostvariti preko serijskog RS232C interfejsa.

Mali softverski paket, koji je instaliran u sistem Spider 8, radi pod operativnim sistemom MS Windows i omogućava akviziciju mernih podataka (kontinuiranu ili periodičnu) i njihovo snimanje $u$ datoteke. Različiti formati datoteka omogućavaju da podacima može da se pristupi različitim aplikacijama. HBM je razvio i softverski paket CATMAN koji omogućava [3]: proizvoljno definisanje načina na koji će se prikazati rezultati merenja, potpunu (trenutnu i naknadnu) analizu rezultata, proizvoljnu interakciju između korisnika i softvera, kontrolu i pomoć pri merenju. 


\section{Zaključak}

U inženjerskoj praksi često se javlja potreba za merenjem nivoa torzionih oscilacija, kako na nekom modelu, tako i na realnom objektu. Izbor metodologije merenja zavisi od više faktora, a pre svega od: cilja merenja, raspoložive merne opreme, tehničko-tehnoloških uslova merenja, obučenosti kadrova, i dr.

Ukoliko je osnovni cilj merenja provera nivoa naprezanja elemenata sistema zbog prisustva torzionih oscilacija, kao i određivanje kritičnih brzina sistema, uspešno se može primeniti metod merenja torzionih oscilacija na osnovu merenja torzionog napona. Upotrebom savremene merne opreme, kakvu je razvio HBM (Hottinger Baldwin Messtechnik), mogu se, u velikoj meri, prevazići problemi koji prate upotrebu mernih traka (osnovni signal ima visoku frekvenciju i male amplitude, a superponiran je šumom).

Merni sistem Spider 8 predstavlja mobilnu mernu opremu malih gabarita, koja omogućava paralelno merenje više dinamičkih veličina pomoću računara. Softverski paket CATMAN, koji se isporučuje zajedno sa mernom opremom, pruža korisniku širok spektar mogućnosti, naročito u pogledu obrade i prikaza rezultata merenja.

\section{Literatura:}

[1] Jankov, R.: Simulacija i eksperimentalno ispitivanje torzionih oscilacija, Mašinski fakultet u Beogradu, 2002.

[2] Hoffmann, K.: An introduction to measurements using strain gages, Hottinger Baldwin Messtechnik GmbH, Darmstadt, 1989.

[3] Hottinger Baldwin Messtechnik: HBM measurement techniques and catman, katalozi firme HBM, Darmstadt, 2001.

[4] Rašković, D.: Otpornost materijala, Građevinska knjiga, Beograd, 1990.

[5] Trifković, D.: Istraživanje torzionih oscilacija u sistemu prenosa snage sa brodskog dizel motora na propeler, Magistarski rad, Mašinski fakultet u Beogradu, 2003. 
a)

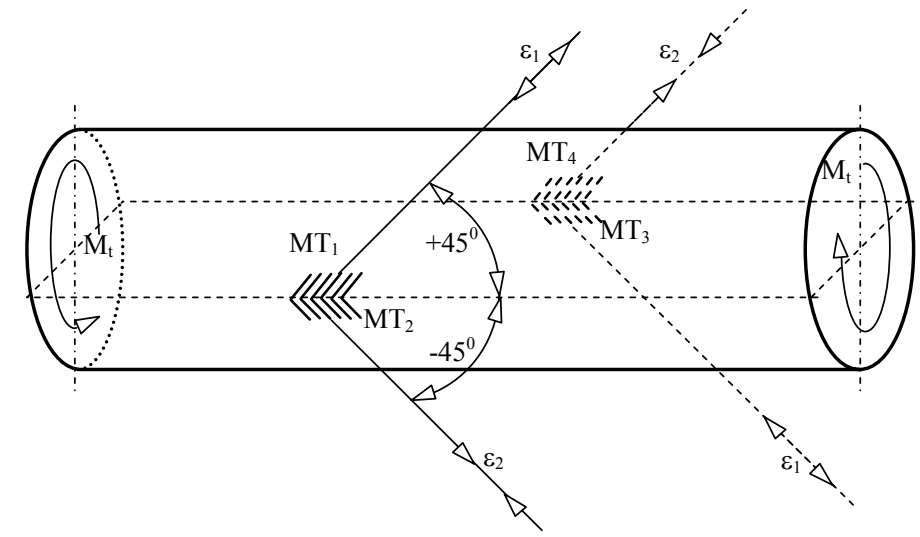

b)
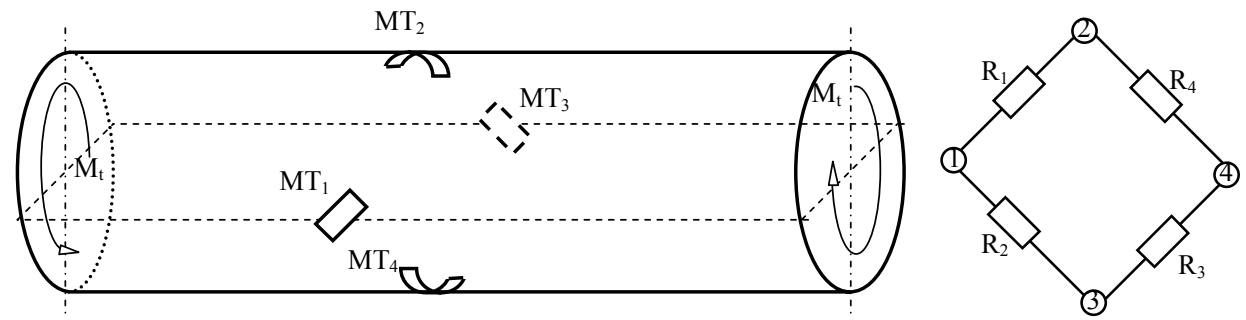

Sl. 1 - Vratilo sa postavljenim mernim trakama i njihove pozicije na mernom mostu, pri primeni: a) specijalnih X rozeta, b) pojedinačnih mernih traka
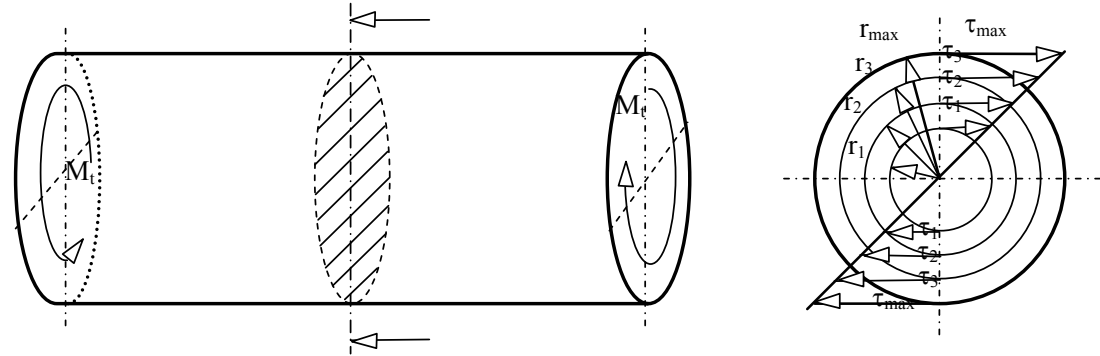

Sl. 2 - Raspored tangencijalnog napona po poprečnom preseku vratila 


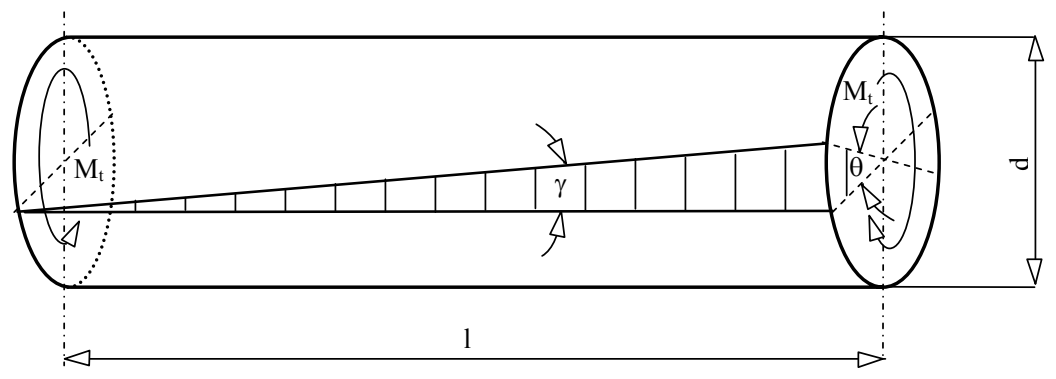

Sl. 3 - Deformacije vratila pri uvijanju 


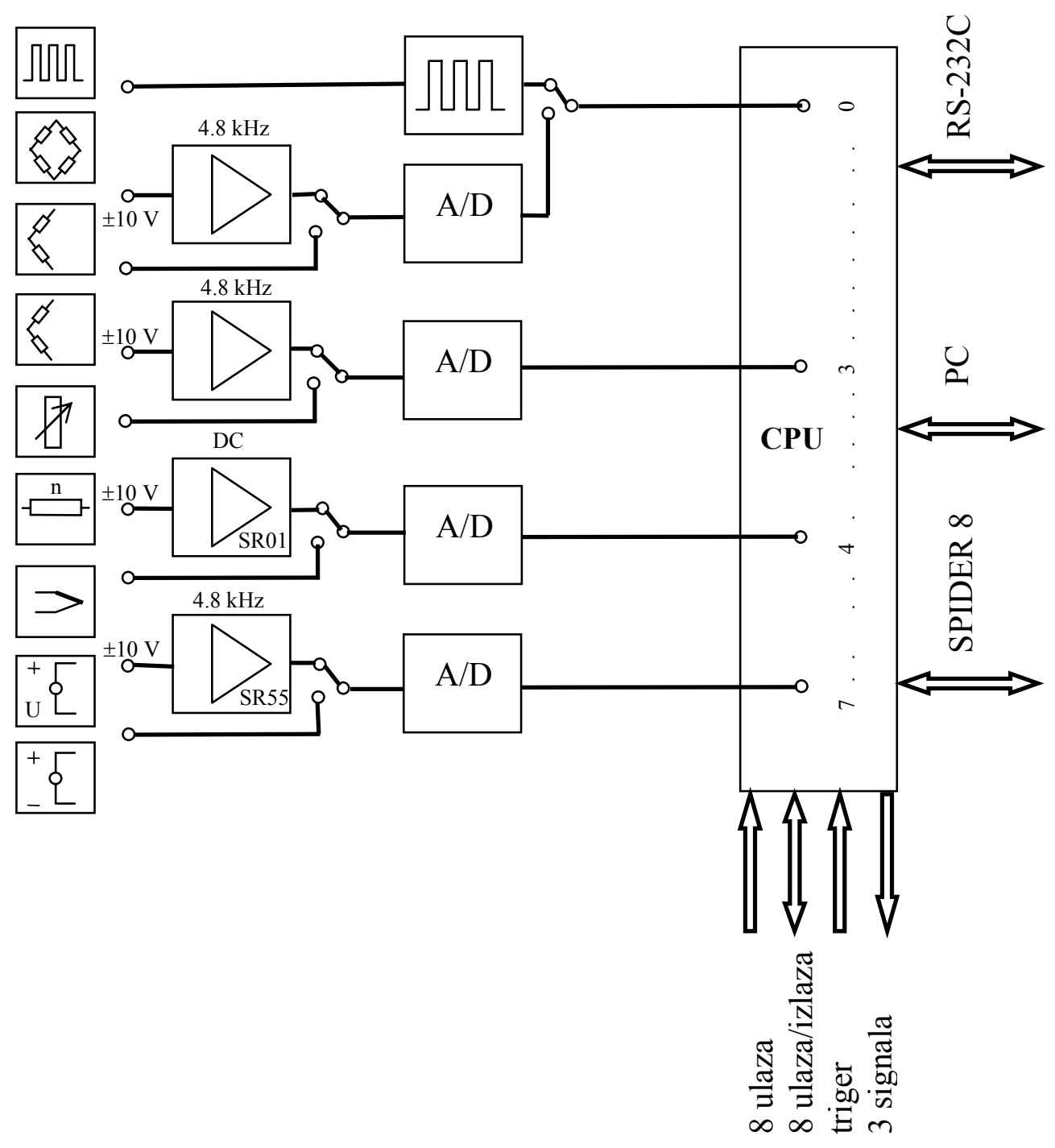

Sl. 4 - Strukturna šema mobilnog mernog sistema SPIDER 8 